\title{
Volumetric motion quantification by 3D velocity encoded MRI
}

\author{
Anja Lutz', Jan Paul', Axel Bornstedt ${ }^{1}$, Gerd Ulrich Nienhaus², Patrick Etyngier ${ }^{3}$, Peter Bernhardt', \\ Wolfgang Rottbauer ${ }^{1}$, Volker Rasche ${ }^{1 *}$ \\ From 15th Annual SCMR Scientific Sessions \\ Orlando, FL, USA. 2-5 February 2012
}

\section{Summary}

It is objective to show the feasibility of volumetric velocity-encoded MRI (3D-TPM) to derive velocity based motion quantification parameters.

\section{Background}

About 30\% of patients treated with cardiac resynchronization therapy (CRT) do not benefit from the procedure. The introduction of quantitative parameters for selection of patients appears mandatory. However, parameters based on 2D imaging techniques may be less reproducible caused by rapid changes of the motion pattern along the cardiac axis.

\section{Methods}

12 volunteers ( $26 \pm 7$ years) and 2 patients $(46, \mathrm{DCM} / 29$, LBBB) were investigated at a $3 \mathrm{~T}$ whole body MR scanner (Achieva, Philips) with a 32 channel cardiac coil. A 3D black blood velocity encoded navigated segmented gradient echo sequence (3D-TPM) was applied for whole heart coverage. The acquisition parameters were: $F O V=380^{2} \mathrm{~mm}^{2}$, isotropic resolution of $3 \times 3 \times 3 \mathrm{~mm}^{3}$, FOV in through-plane direction $=63 \mathrm{~mm}$ in healthy volunteers (this FOV was increased in patients due to their enlarged heart corresponding to the distance between basis and apex), acquisition matrix $=128 \times 124$, TR/ $\mathrm{TE}=7.1 \mathrm{~ms} / 4.9 \mathrm{~ms}$, flip angle $=15^{\circ}$, SENSE $=4$, nominal scan duration $=15: 30$ minutes, $3 \mathrm{k}$-lines per segment, phase interval $=37.3 \mathrm{~ms}$ and 25 cardiac phases for $60 \mathrm{bpm}$. The acquisition of the whole heart data was split into 3 chunks to ensure sufficient black blood contrast.

${ }^{1}$ University Hospital of Ulm, UIm, Germany

Full list of author information is available at the end of the article
From the 3D-TPM data, the following parameters were evaluated: longitudinal and radial standard deviation of time to peak systolic and diastolic velocities SD $\left(\mathrm{TTP}_{1, \text { sys }}\right), \mathrm{SD}\left(\mathrm{TTP}_{1, \text { dias }}\right), \mathrm{SD}\left(\mathrm{TTP}_{\mathrm{r}, \mathrm{sys}}\right), \mathrm{SD}\left(\mathrm{TTP}_{\mathrm{r}, \text { dias }}\right)[1]$, the mean radial, circumferential and longitudinal asynchrony correlation coefficient over all cardiac segments (ACC)[2], the longitudinal and radial velocity range $\Delta \mathrm{v}_{\mathrm{l}}$ $=\mathrm{v}_{\mathrm{l}, \max }-\mathrm{v}_{\mathrm{l}, \min }, \Delta \mathrm{v}_{\mathrm{r}}=\mathrm{v}_{\mathrm{r}, \text { max }}-\mathrm{v}_{\mathrm{r}, \text { min }}$ and the new parameter temporal uniformity of velocity (TUV) in radial, longitudinal and circumferential direction, which was defined analogously to the temporal uniformity of strain defined in $[3,4]$.

\section{Results}

Figure 1 shows the 3D velocity over time curves exemplarily for one volunteer and patient 2 with proven asynchrony. A clearly modified motion pattern with reduced peak velocities can be appreciated as well as the large variation of the motion curve along the heart axes in the volunteer. Table 1 contains the motion quantification parameter evaluation based on 3D-TPM data as mean \pm standard deviation for the volunteer group and the patients. The mean ACC over all segments is decreased and the velocity ranges and TUV are decreased in the patients compared to healthy volunteers. $\mathrm{SD}\left(\mathrm{TTP}_{\text {sys,r }}\right)$ is increased in case of asynchrony.

\section{Conclusions}

It is feasible to determine motion quantification parameters based on 3D velocity data. Huge differences could be observed between asynchronous patients and volunteers. A study including more patients is necessary to decide whether 3D -TPM data may in future distinguish between responders and non-responders to CRT.
C Biomed Central 

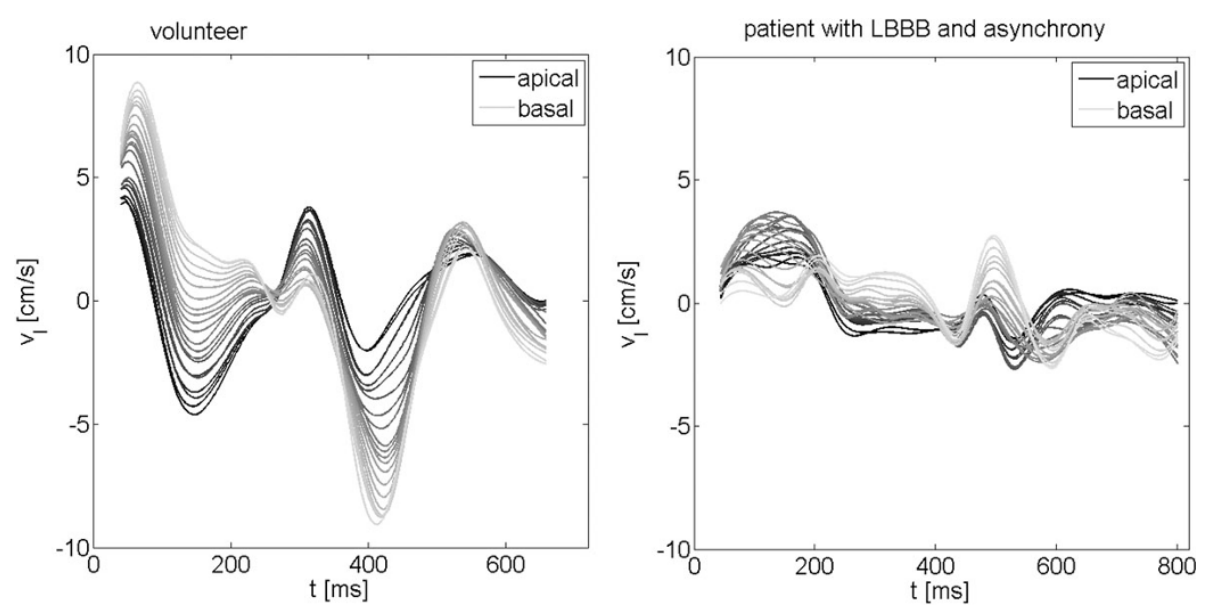

Figure 1 Velocity over time curves resulting from 3D TPM data exemplarily for one volunteer and one patient with LBBB and asynchrony

Table 1 Velocity based motion parameters evaluated for all volunteers (mean \pm standard deviation) and for investigated patients.

\begin{tabular}{|c|c|c|c|c|}
\hline \multirow[t]{2}{*}{ parameter } & \multicolumn{2}{|c|}{ volunteers } & \multirow{2}{*}{$\begin{array}{c}\text { patient } 1 \\
{[\mathrm{DCM}]}\end{array}$} & \multirow{2}{*}{$\frac{\text { patient } 2}{[\mathrm{LBBB} \text {, asynchrony }}$} \\
\hline & mean & $\sigma$ & & \\
\hline $\mathrm{SD}(\mathrm{TTP})_{\mathrm{l}, \mathrm{sys}}[\mathrm{ms}]$ & 37.08 & 22.49 & 24.02 & 56.73 \\
\hline $\mathrm{SD}(\mathrm{TTP})_{\mathrm{l}, \mathrm{dias}}[\mathrm{ms}]$ & 19.52 & 3.78 & 6.04 & 54.10 \\
\hline $\mathrm{SD}(\mathrm{TTP})_{\mathrm{r}, \mathrm{sys}}[\mathrm{ms}]$ & 42.41 & 8.08 & 48.69 & 80.89 \\
\hline $\mathrm{SD}(\mathrm{TTP})_{\mathrm{r}, \mathrm{dias}}[\mathrm{ms}]$ & 37.90 & 7.44 & 26.00 & 51.40 \\
\hline mean $\mathrm{ACC}_{\mathrm{I}}$ & 0.90 & 0.02 & 0.77 & 0.58 \\
\hline mean $\mathrm{ACC}_{\mathrm{r}}$ & 0.71 & 0.06 & 0.55 & 0.40 \\
\hline mean $\mathrm{ACC}_{\mathrm{c}}$ & 0.72 & 0.04 & 0.52 & 0.34 \\
\hline mean $\Delta v_{1}[\mathrm{~cm} / \mathrm{s}]$ & 13.40 & 2.30 & 7.07 & 4.66 \\
\hline mean $\Delta v_{r}[\mathrm{~cm} / \mathrm{s}]$ & 7.20 & 0.78 & 3.42 & 4.45 \\
\hline $\mathrm{TUV}_{\mathrm{I}}$ & 0.86 & 0.01 & 0.74 & 0.74 \\
\hline TUV $_{r}$ & 0.78 & 0.02 & 0.71 & 0.66 \\
\hline $\operatorname{TUV}_{c}$ & 0.77 & 0.03 & 0.69 & 0.62 \\
\hline
\end{tabular}

\section{Funding}

AL and VR have a research agreement with Philips Healthcare. PE is employed by Philips Healthcare.

\section{Author details}

${ }^{1}$ University Hospital of UIm, Ulm, Germany. ${ }^{2}$ Karlsruhe Institute of Technology, Karlsruhe, Germany. ${ }^{3}$ Medisys Research Lab, Philips Healthcare,

Suresnes, France.

Published: 1 February 2012

\section{References}

1. Föll , et al: J Magn Reson Imaging. 2011.

2. Schneider, et al: J Comput Assist Tomogr. 2001, 25:550-557.

3. Bilchick, et al: JACC Cardiovasc Imaging. 2008, 1:561-568.

4. Leclercq, et al: Circulation. 2002, 106:1760-1763.

\section{doi:10.1186/1532-429X-14-S1-P247}

Cite this article as: Lutz et al:: Volumetric motion quantification by 3D velocity encoded MRI. Journal of Cardiovascular Magnetic Resonance 2012 14(Suppl 1):P247.
Submit your next manuscript to BioMed Central and take full advantage of:

- Convenient online submission

- Thorough peer review

- No space constraints or color figure charges

- Immediate publication on acceptance

- Inclusion in PubMed, CAS, Scopus and Google Scholar

- Research which is freely available for redistribution

Submit your manuscript at www.biomedcentral.com/submit 